\title{
S1P lyase regulates DNA damage responses through a novel sphingolipid feedback mechanism
}

\author{
A Kumar ${ }^{1}$, B Oskouian ${ }^{1}$, H Fyrst ${ }^{1}$, M Zhang ${ }^{1}$, F Paris ${ }^{2}$ and JD Saba ${ }^{\star, 1}$
}

The injurious consequences of ionizing radiation (IR) to normal human cells and the acquired radioresistance of cancer cells represent limitations to cancer radiotherapy. IR induces DNA damage response pathways that orchestrate cell cycle arrest, DNA repair or apoptosis such that irradiated cells are either repaired or eliminated. Concomitantly and independent of DNA damage, IR activates acid sphingomyelinase (ASMase), which generates ceramide, thereby promoting radiation-induced apoptosis. However, ceramide can also be metabolized to sphingosine-1-phosphate (S1P), which acts paradoxically as a radioprotectant. Thus, sphingolipid metabolism represents a radiosensitivity pivot point, a notion supported by genetic evidence in IR-resistant cancer cells. S1P lyase (SPL) catalyzes the irreversible degradation of S1P in the final step of sphingolipid metabolism. We show that SPL modulates the kinetics of DNA repair, speed of recovery from G2 cell cycle arrest and the extent of apoptosis after IR. SPL acts through a novel feedback mechanism that amplifies stress-induced ceramide accumulation, and downregulation/ inhibition of either SPL or ASMase prevents premature cell cycle progression and mitotic death. Further, oral administration of an SPL inhibitor to mice prolonged their survival after exposure to a lethal dose of total body IR. Our findings reveal SPL to be a regulator of ASMase, the G2 checkpoint and DNA repair and a novel target for radioprotection.

Cell Death and Disease (2011) 2, e119; doi:10.1038/cddis.2011.3; published online 10 February 2011

Subject Category: Cancer

The genomic integrity of eukaryotic cells is maintained by a DNA damage response (DDR) that includes DNA repair mechanisms combined with cell cycle checkpoints. ${ }^{1}$ The G2 checkpoint is activated by double-stranded breaks or a region of single-stranded DNA caused by chemical agents, ionizing radiation (IR) or stalled replication forks generated during $\mathrm{S}$ phase. Progression from the $\mathrm{G} 2$ phase to mitosis is mediated by the cyclin-dependent kinase 1 (Cdk1)-cyclin B complex. This complex is activated late in $\mathrm{G} 2$, driving the cell into mitosis. In the presence of DNA damage, DNA repair mechanisms are activated and the Cdk1-cyclin B complex is held in check, thereby initiating the G2 checkpoint. If the extent of DNA damage overwhelms the capability of the repair machinery, the DDR induces signaling pathways resulting in apoptosis. Although much is known regarding the signaling events that converge on the DDR, molecular events involved in initiation, maintenance, adaptation and reversal of the $\mathrm{G} 2$ checkpoint and the Cdk1-cyclin B complex have not been fully elucidated. ${ }^{2}$

Sphingolipid metabolites are ubiquitous regulators of the cellular response to stress. Ceramide is a sphingolipid metabolite that accumulates in irradiated cells and the serum of irradiated patients. ${ }^{3-6}$ This is due largely to the radiationinduced hydrolysis of sphingomyelin (SM) by sphingomyelinases (SMases) that are activated immediately after IR exposure independently of DNA damage. ${ }^{6-8}$ Ceramide disrupts membrane rafts, induces apoptotic signaling cascades and contributes to epithelial and endothelial cell death. ${ }^{9}$ Inhibition of ceramide formation has been proposed as a method to prevent radiation-induced cell and tissue injury. Reducing ceramide accumulation by blocking SMase or through genetic deletion of the acid sphingomyelinase (ASMase) gene SMPD1 attenuates IR injury in rodent models. ${ }^{10,11}$

Ceramide can be further metabolized to sphingosine-1phosphate (S1P) via formation of the biochemical intermediate, sphingosine. S1P is a bioactive lipid that acts through both receptor-mediated and intracellular signaling mechanisms to promote cell proliferation and survival and block apoptosis. ${ }^{12} \mathrm{~S} 1 \mathrm{P}$ acts as a radioprotectant, preventing oocyte apoptosis and sterility in irradiated mice. ${ }^{13,14} \mathrm{~S} 1 \mathrm{P}$ is irreversibly degraded by the intracellular enzyme, S1P lyase (SPL). ${ }^{15} \mathrm{SPL}$ is induced by DNA damage and other stressful conditions. $^{16}$ Increased expression and activity of SPL promote apoptosis, whereas inhibiting SPL in cells reduces apoptosis in response to genotoxic and other stresses. ${ }^{16-19}$

In this study, we investigated the effect of IR on SPL and the role of SPL in mediating the DDR. We show that SPL is a radiation-responsive protein whose expression regulates maintenance of the G2 checkpoint and radiation-induced apoptosis through a mechanism involving both S1P and ceramide. Our findings establish the existence of a novel

\footnotetext{
${ }^{1}$ Center for Cancer Research, Children's Hospital Oakland Research Institute, 5700 Martin Luther King Jr. Way, Oakland, CA, USA and ${ }^{2}$ INSERM, Oncology Research Department, Nantes, France

${ }^{*}$ Corresponding author: JD Saba, Center for Cancer Research, Children's Hospital Oakland Research Institute, 5700 Martin Luther King Jr. Way, Oakland, CA 94609-1673, USA. Tel: 510450 7690; Fax: 510450 7910; E-mail: jsaba@chori.org

Keywords: S1P lyase; sphingosine 1-phosphate; radiation; sphingomyelinase; DNA damage; cell cycle arrest

Abbreviations: DDR, DNA damage response; CDK1, cyclin-dependent kinase 1; IR, ionizing radiation; SM, sphingomyelin; SMase, sphingomyelinase; ASMase, acid sphingomyelinase; S1P, sphingosine-1-phosphate; SPL, sphingosine-1-phosphate lyase; S10-H3, Ser10-phosphohistone-H3; THI, tetrahydroxybutylimidazole; TBI, total body irradiation; ATM, ataxia telengiectasia mutated; Chk1, checkpoint kinase 1

Received 12.8.10; revised 15.11.10; accepted 13.12.10; Edited by P Salomoni
} 
sphingolipid feedback loop and reveal SPL to be a regulator of DDRs and a potential target for radioprotection.

\section{Results}

SPL is a radioresponsive protein that potentiates cell death after IR. To determine whether IR influences SPL expression, we subjected human embryonic kidney (HEK293T) cells and NIH3T3 fibroblasts to 10 Gy IR and SPL protein levels were examined by immunoblotting. As shown in Figure 1a, SPL protein levels were elevated in response to IR in both cell lines. SPL induction in response to IR was even more pronounced at higher dose (Supplementary Figure 1). In contrast to SPL protein levels, SPL message levels were not consistently altered under these conditions (data not shown), which suggests that SPL protein accumulates in response to IR through a translational or posttranslational mechanism. To investigate the ramifications of SPL upregulation on irradiated cells, HEK293T cells exhibiting constitutively high SPL activity by virtue of stable overexpression of human SPL (SPL ${ }^{\text {hi }}$ cells) and HEK293T vector control cells containing low endogenous SPL levels ${ }^{17}$ were irradiated, and apoptosis was evaluated. As shown in Figure $1 \mathrm{~b}, \mathrm{SPL}^{\text {hi }}$ cells exhibited enhanced sensitivity to IR as shown by an increase in apoptosis measured by caspase-3 activity and by the presence of PARP cleavage products (Figure 1c) and subG1 peak (Figure 1d). To determine the role of SPL in apoptotic signaling pathways, cytochrome $c$ release into the cytosol was examined by immunoblotting. In response to IR, SPL ${ }^{\text {hi }}$ cells and control cells both released cytochrome $c$ into the cytoplasm (Supplementary Figure 2). However, SPL ${ }^{\text {hi }}$ cells showed greater cytochrome $c$ release into the cytosol compared with control cells. Further, treatment with inhibitors of caspases, including those involved in extrinsic (caspase-8) a

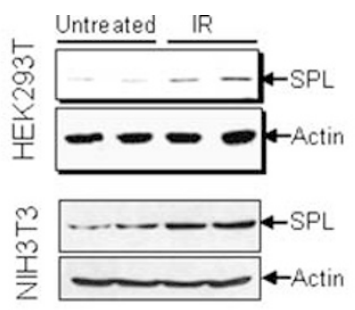

C
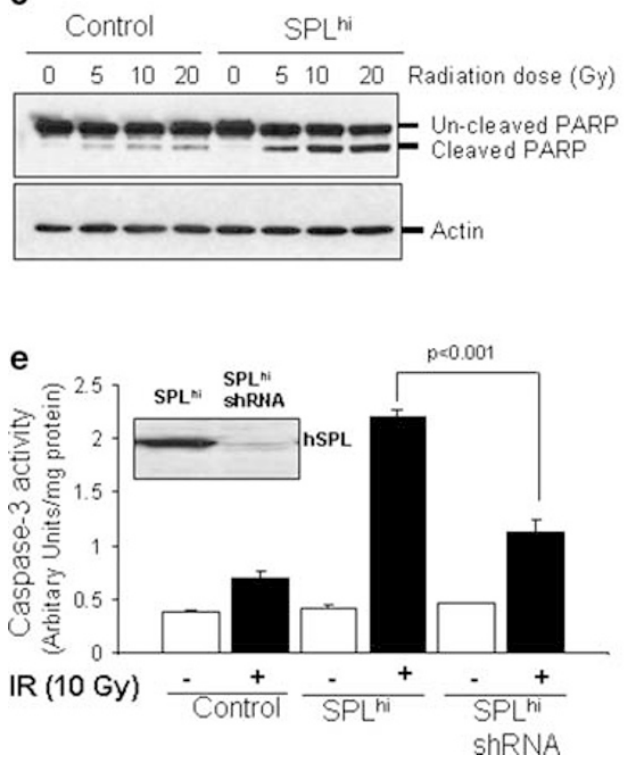

b

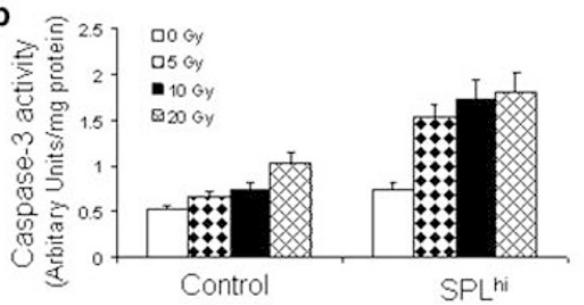

d

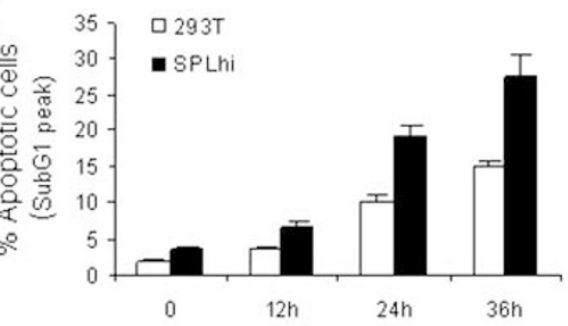

f

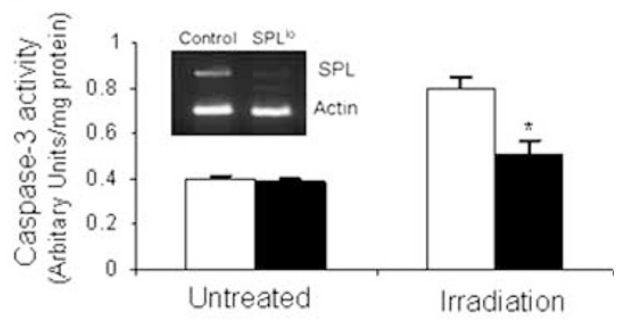

Figure 1 SPL is a radioresponsive protein that increases radiation-induced cell death. (a) HEK293T and NIH3T3 cells were left untreated or irradiated with 10 Gy of X-rays. Cells were harvested $9 \mathrm{~h}$ (HEK293T) or $24 \mathrm{~h}$ (NIH3T3) after radiation exposure and whole cell lysate was immunoblotted with actin and anti-human SPL, or anti-murine SPL antibodies, respectively. (b and $\mathbf{c}$ ) Control and SPL hi cells were exposed with indicated dose of IR. After $24 \mathrm{~h}$ of incubation, cells were harvested, and apoptosis was assessed by measuring caspase-3 activity (b) and cell lysate was immunoblotted for PARP (Poly (ADP-ribose) polymerase). (c) Caspase-3 activity experiment represents mean \pm S.D. of three independent experiments. The immunoblot is representative of at least three independent experiments. (d) Control and SPL ${ }^{\text {hi }}$ cells were left untreated or subjected to 5 Gy dose of X-rays and cells were harvested 12,24 and $36 \mathrm{~h}$ after radiation exposure. Apoptosis was determined by flow cytometry using propidium iodide staining. Values

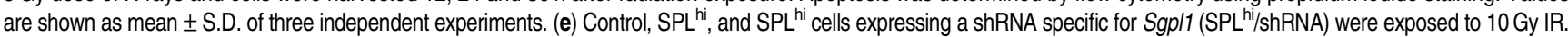
After $24 \mathrm{~h}$ of incubation, caspase-3 activity was measured in whole cell lysate. Sgpl 1 knockdown was confirmed by western blotting (inset). Data represents mean \pm S.D. of three different experiments done in duplicates. (f) Endogenous knockdown of Sgpl1 induces radio-resistance. HEK293T control cells with lentiviral vector (control, open bar) or with shRNA specific for sgpl1 (SPL ${ }^{10}$; solid bar) were exposed to $10 \mathrm{~Gy} \mathrm{X}$-rays and caspase-3 activity was measured $36 \mathrm{~h}$ after radiation exposure. Sgp/1 knockdown was confirmed by RT-PCR (inset). Data are shown as mean \pm S.D. $\left(n=3,{ }^{*} P<0.01\right)$. Each experiment was repeated at least three times. Data points indicate average \pm S.D. of representative experiment 
and intrinsic (caspase-9) apoptotic pathways, attenuated radiation-induced apoptosis in SPLi cells, as shown in Supplementary Figure 3. To confirm that the IR-sensitive phenotype of SPL hi cells is specifically attributed to SPL overexpression and not an acquired genetic modification associated with stable transformation, SPL overexpression was reversed by lentiviral expression of a shRNA molecule that specifically targeted human SPL. As shown in Figure 1e, SPL knockdown reversed the radiosensitive phenotype of SPL hi cells. Further, knockdown of endogenous SPL in HEK293T cells (SPL ${ }^{\text {lo }}$ cells) conferred an IR-resistant phenotype, demonstrating a role for endogenous SPL in radiation-induced apoptosis (Figure 1f). Together, these findings reveal SPL to be a radiation-responsive protein that sensitizes cells to IR through an apoptotic pathway or pathways involving mitochondrial permeability transition and activation of caspases.

SPL promotes premature release from cell cycle arrest after IR. Cell cycle arrest is a critical component of the DDR that allows cells sufficient time to repair damaged DNA molecules before entry into mitosis, thereby insuring genomic integrity. We examined the effect of SPL on cell cycle arrest after IR using propidium iodide staining coupled with flow cytometry. Both control and SPL ${ }^{\text {hi }}$ cells exhibited a normal cell cycle distribution at baseline, and both arrested appropriately in $\mathrm{G} 2$, as shown by a large peak of cells containing $4 \mathrm{~N}$ DNA content $12 \mathrm{~h}$ after treatment with $10 \mathrm{~Gy}$ IR (Figure 2a). These findings suggest that SPL does not interfere with the initiation of $\mathrm{G} 2$ cell cycle arrest in response to DNA damage. However, whereas control cells maintained the $\mathrm{G} 2$ arrest for $24 \mathrm{~h}$, as shown by a single population of cells containing $4 \mathrm{~N}$ DNA content, analysis of SPL ${ }^{\text {hi }}$ cells $24 \mathrm{~h}$ after IR revealed two peaks, one representing cells with $4 \mathrm{~N}$ DNA content and one representing cells with $2 \mathrm{~N}$ DNA content. These findings indicate that a population of SPL ${ }^{\mathrm{hi}}$ cells had entered $\mathrm{G} 1$ phase at this time point. The $4 \mathrm{~N}$ peak in the cell cycle histogram does not distinguish between cells in $\mathrm{G} 2$ versus $\mathrm{M}$ phase. Therefore, to identify cells in mitosis, we performed immunoblotting for the mitotic marker Ser10phosphohistone-H3 (S10-H3) in comparison with total histone-H3. As shown in Figure $2 b$, control irradiated cells contained reduced levels of $\mathrm{S} 10-\mathrm{H} 3$ compared with untreated cells $12 \mathrm{~h}$ through $24 \mathrm{~h}$ after IR, consistent with induction and maintenance of $\mathrm{G} 2$ cell cycle arrest in response to DNA damage. SPL ${ }^{\text {hi }}$ cells treated with IR also demonstrated reduced $\mathrm{S} 10-\mathrm{H} 3$ levels $12 \mathrm{~h}$ after IR. However, by 18 and $24 \mathrm{~h}$ the $\mathrm{S} 10-\mathrm{H} 3$ levels in SPL ${ }^{\text {hi }}$ cells had recovered, indicating the presence of a significant population of cells in mitosis. In contrast, there was no appreciable difference in total histone-H3 levels in the two cell lines. Mitotic index was quantified by immunocytometry as well as by immunofluorescent staining using a S10-H3 antibody (Figure 2c and Supplementary Figure 4). SPL ${ }^{\text {hi }}$ cells exhibited a high mitotic index at baseline as well as after IR in comparison with control cells, whereas irradiated SPL ${ }^{\text {lo }}$ cells exhibited a lower mitotic index than irradiated control cells. Importantly, knockdown of SPL restored the ability of SPL ${ }^{\mathrm{hi}}$ cells to maintain G2 arrest after IR (Figure 2d). Together, these findings demonstrate that SPL does not interfere with initiation of $\mathrm{G} 2$ arrest but prevents the maintenance of $\mathrm{G} 2$ arrest, leading to premature entry into mitosis after genotoxic injury.

SPL expression affects the Cdk1-cyclin B complex. The G2 to $M$ transition is controlled by the Cdk1-cyclin B complex, and premature activation of this complex can lead to inappropriate cell cycle progression and radiation-induced mitotic catastrophe. ${ }^{20}$ Therefore, we examined the influence of SPL expression on both components of this kinase complex. Compared with control cells, SPL ${ }^{\text {hi }}$ cells demonstrated higher CDK1 and cyclin B1 protein expression beginning $12 \mathrm{~h}$ and continuing through $24 \mathrm{~h}$ after IR (Figure 2b). Mitotic progression in the face of persistent DNA damage could lead to apoptosis of SPLi cells. Consistent with this notion, pretreatment of SPL ${ }^{\text {hi }}$ cells with cell cycle inhibitors (Supplementary Figure 5) and a Cdk1 inhibitor prevented inappropriate cell cycle progression and reversed the IR-sensitivity of $\mathrm{SPL}^{\text {hi }}$ cells, as shown in Figure $2 \mathrm{e}$ and Supplementary Figure 6 . Thus, we conclude that SPL radiosensitizes cells by abbreviating $\mathrm{G} 2$ cell cycle arrest through a Cdk1-cyclin B-dependent mechanism that promotes cell cycle progression and potentiates apoptosis after IR exposure.

SPL sensitizes cells to IR by depleting cellular S1P and elevating ceramide levels. SPL catalyzes the conversion of S1P into hexadecanal and ethanolamine phosphate in the final step of the sphingolipid degradation biochemical pathway. SPL could mediate its radiosensitizing effects by lowering intracellular S1P, by increasing the products of S1P breakdown, or through some indirect effect. As shown in Figure $3 a, S^{2} L^{\text {hi }}$ cells contain low S1P levels. However, addition of S1P did not rescue the IR-induced cell death in $\mathrm{SPL}^{\text {hi }}$ cells (data not shown). To avoid issues related to ineffective delivery of exogenous S1P to cells, we employed a genetic strategy to increase intracellular S1P through overexpression of sphingosine kinase 1 (SK1). As shown in Figures $3 b$ and $c$, the IR-sensitivity of SPL ${ }^{\text {hi }}$ cells was partially reversed by SK1 overexpression. These findings indicate that S1P depletion is partially but not completely responsible for the effect of SPL on radiation responses. Radiation-induced ceramide generation contributes to cellular apoptosis and acute radiation syndromes. ${ }^{7}$ Therefore, we also measured intracellular ceramide content at baseline and after IR of control and SPL ${ }^{\text {hi }}$ cells via mass spectrometry (Table 1). As expected, both cell lines showed an increase in ceramide levels after IR. Surprisingly, however, SPL ${ }^{\text {hi }}$ cells contained $50 \%$ greater ceramide content compared with control cells under baseline conditions as well as after IR. Immunofluorescent staining of permeabilized cells using a ceramide-specific antibody further confirmed the high ceramide levels in SPL ${ }^{\text {hi }}$ cells compared with control cells (Figures $3 d$ and e). These findings confirm that SPL expression leads to an increase in ceramide levels. Ceramide can be generated by de novo biosynthesis or hydrolysis of membrane sphingomyelin. To explore whether SPL radiosensitizes cells in a ceramide-dependent fashion, apoptosis was quantitated in irradiated control and SPL ${ }^{\text {hi }}$ cells that had been treated 
before IR with either desipramine, which causes proteolysis of the ASMase protein and thereby blocks ceramide formation from SM, or inhibitors of de novo ceramide biosynthesis including myriocin (which inhibits serine palmitoyltransferase) or fumonisin B1 (which inhibits ceramide synthase). As shown in Figure 4a, only desipramine pretreatment blocked apoptotic responses to IR in SPL ${ }^{\text {hi }}$ cells, indicating that SPL promotes IR-induced apoptosis through a process involving ASMase-dependent generation of ceramide from SM
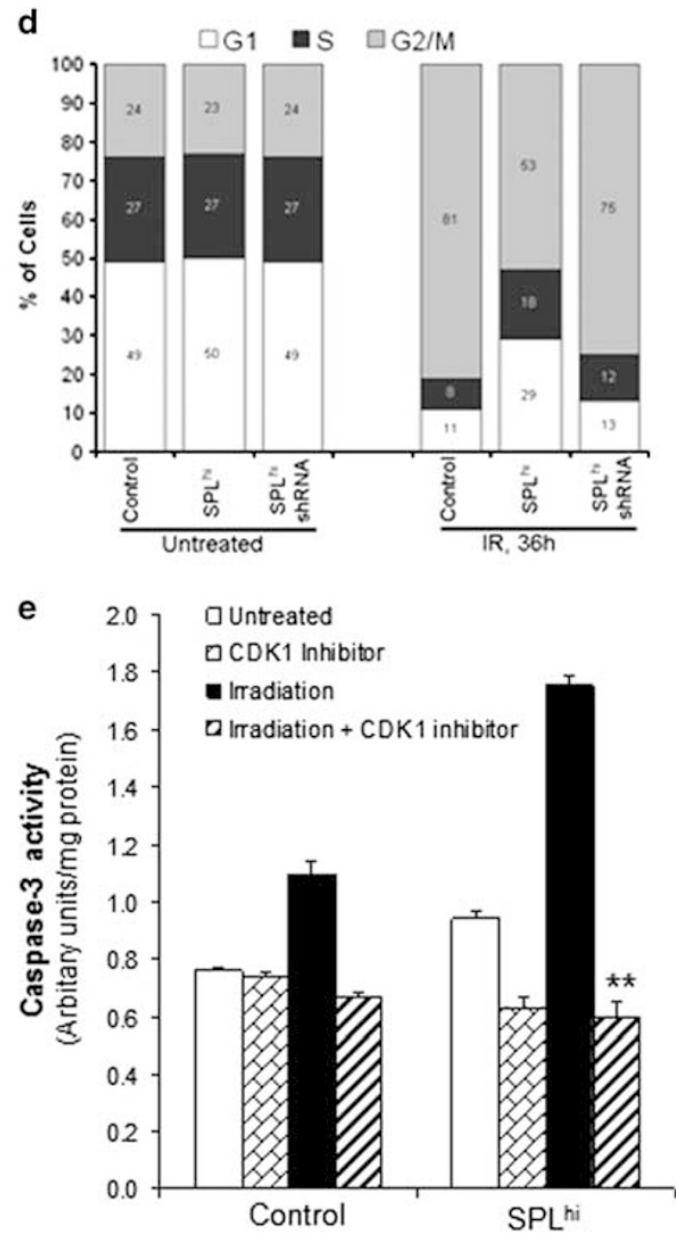
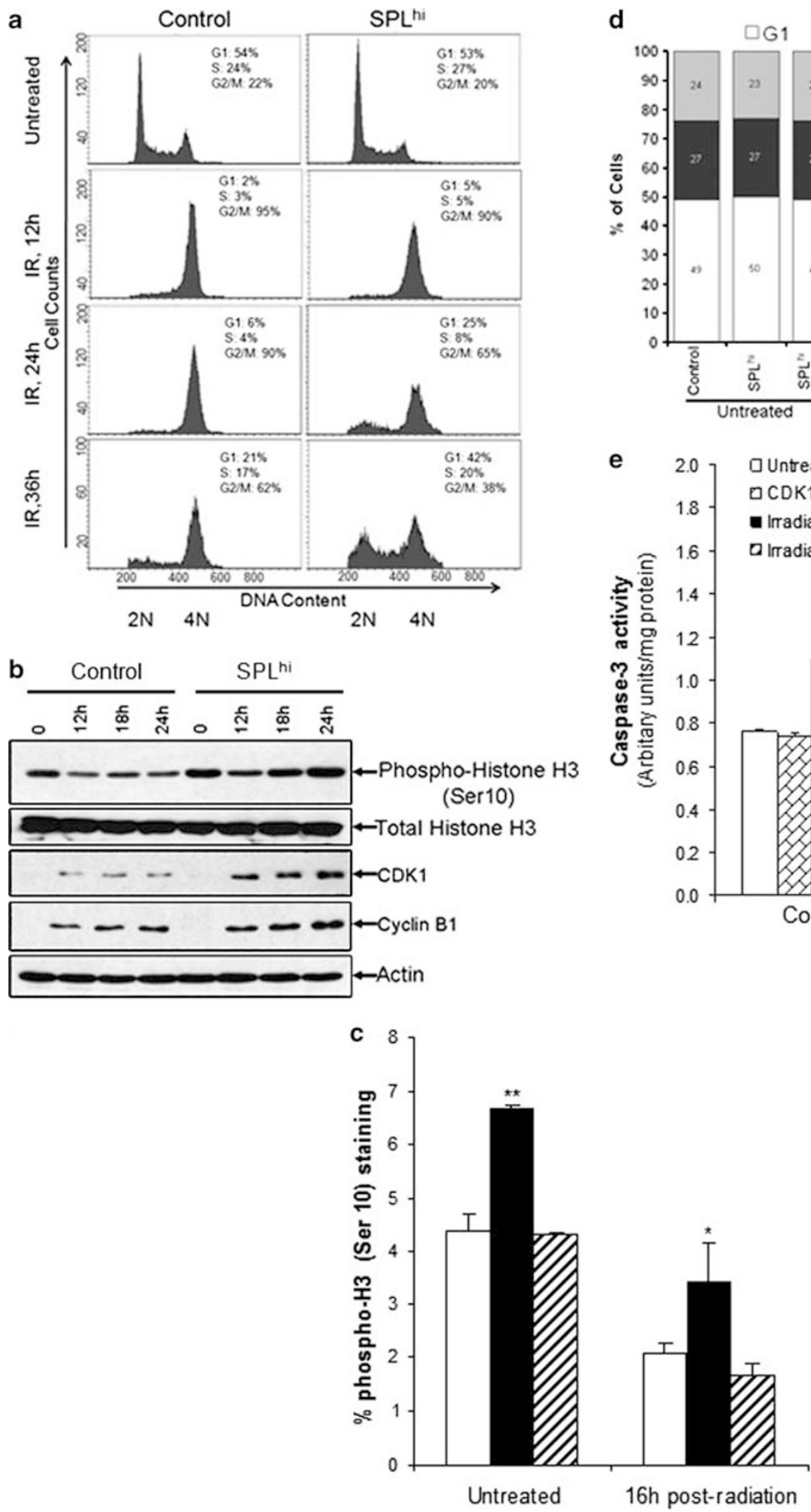
SPL expression augments cellular levels and activity of ASMase. Neutral, acidic and alkaline SMase enzymes are responsible for metabolizing membrane and dietary SM to form ceramide. However, the localized expression pattern of alkaline SMase makes it an unlikely source of ceramide in our model system. Therefore, we examined the effect of SPL expression on both acidic and neutral SMase activities before and after IR. As shown in Figure 4b, ASMase activity was $50 \%$ higher in SPL ${ }^{\text {hi }}$ cells than in control cells. As expected, ASMase activity was reduced to negligible levels in SPL hi cells treated with desipramine. In contrast, neutral SMase activity was unaffected by SPL expression (Figure 4c). To determine the etiology of elevated ASMase activity in SPL hi cells, we evaluated ASMase protein expression by immunoblotting. As shown in Figure $4 \mathrm{~d}$, ASMase protein levels were higher in SPL ${ }^{\text {hi }}$ cells compared with control cells. To confirm this finding, confocal microscopy was performed on fixed, nonpermeabilized control and SPL ${ }^{\text {hi }}$ cells stained with an ASMase-specific antibody. As shown in Figures $4 \mathrm{e}$ and $\mathrm{f}, \mathrm{SPL}{ }^{\text {hi }}$ cells exhibited a

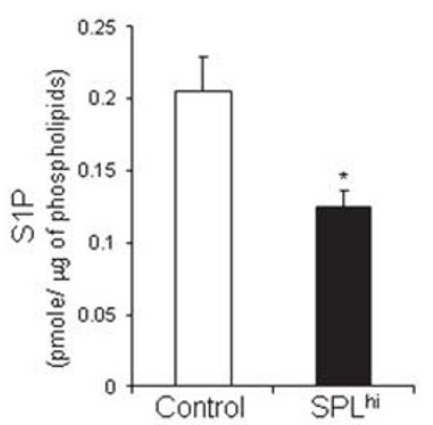

d
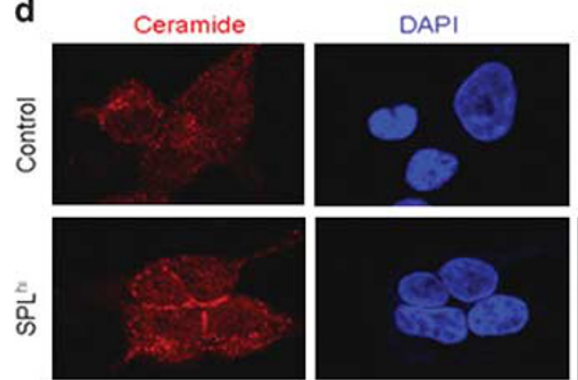

b

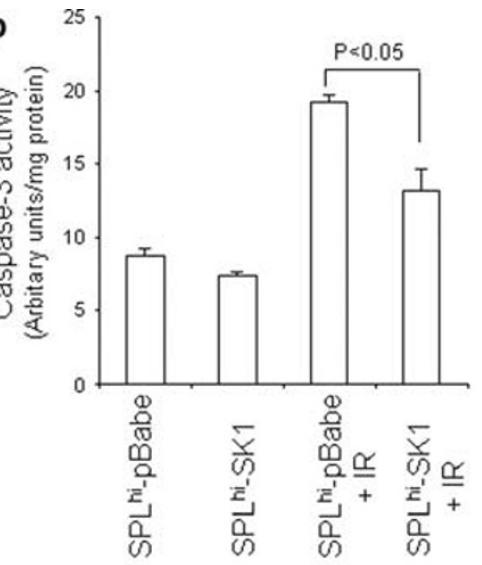

C

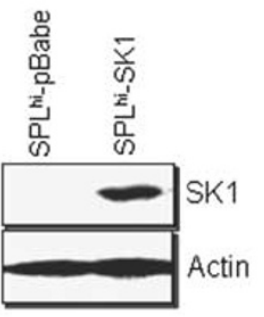

e
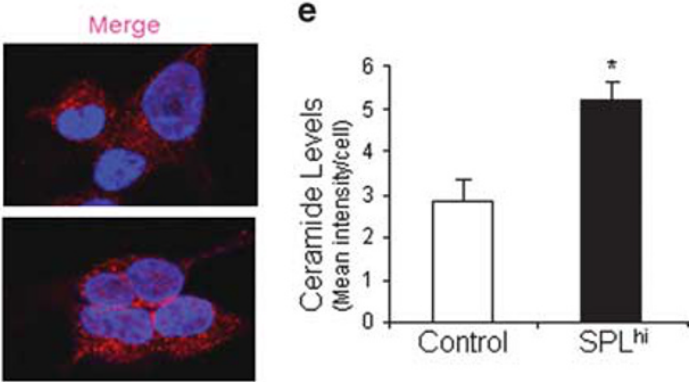

Figure 3 SPL sensitizes cells to apoptosis after DNA damage by depleting S1P and increasing ceramide levels. (a) Total cellular S1P content in control (open bar) and $\mathrm{SPL}^{\text {hi }}$ (solid bar) cells was quantitated by LC-MS and normalized to total phospholipids of whole cell extracts. Data are shown as mean \pm S.D. of three different experiments. ${ }^{*} P<0.01$. (b) Sphk1 (SK1) was overexpressed in $S P L^{\text {hi }}$ cells using a pBabe mammalian expression system. SPL ${ }^{\text {hi }}$ cells with empty vector (SPL ${ }^{\text {hi }}-\mathrm{pBabe}$ ) or $S P L{ }^{\text {hi }}$ cells with

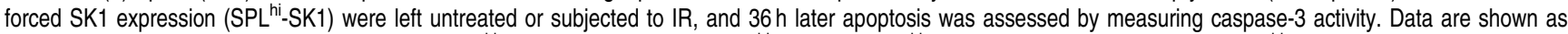
mean \pm S.D. $(n=3)$. (c) Whole cell lysates from SPL ${ }^{\text {hi }}$ cells with empty vector (SPL ${ }^{\text {hi }}$-pBabe) or SPL ${ }^{\text {hi }}$ cells with forced SK1 expression (SPL ${ }^{\text {hi }}$-SK1) were immunoblotted with SK1 or actin antibodies. (d) Control and SPL hi cells were grown on poly-L-lysine coated culture slides for $24 \mathrm{~h}$. Immunolabeling was performed for ceramide in fixed and permeabilized cells. Images were acquired using a laser-scanning microscope (LSM 710). (e) Fluorescence intensity for ceramide was quantitated using NIH ImageJ software. Data are shown as mean \pm S.E.M. $\left(n=2,{ }^{*} P<0.01\right)$

Figure 2 SPL promotes early release from cell cycle arrest and inappropriate entry into mitosis. (a) Control and SPL ${ }^{\text {hi }}$ cells were irradiated with 10 Gy X-rays and harvested at indicated time points. Cell cycle distribution was examined by flow cytometry using PI staining. The percentage of cells in each stage of the cell cycle at $0,12,24$ and $36 \mathrm{~h}$ after irradiation is shown within each histogram. (b) Control and SPL ${ }^{\mathrm{hi}}$ cells were left untreated or irradiated and harvested at the indicated time points, and whole cell extracts were immunoblotted with phospho-histone H3 (Ser10), total histone H3, CDK1, cyclin B1 and actin antibodies. Immunoblots are representative of at least three independent experiments. (c) SPL hi cells exhibits increased mitosis after DNA damage. Control (open bar), SPL ${ }^{\text {hi }}$ (solid bar), and SPL ${ }^{\text {lo }}$ (hatched bar) cells were left untreated or irradiated and cells were harvested $16 \mathrm{~h}$ after radiation exposure. Mitotic index was determined by phospho-histone H3 (Ser 10) staining followed by flow cytometry. Data are shown as mean \pm S.D. $\left(n=3,{ }^{* \star} P<0.01\right.$ for baseline control versus SPL ${ }^{\text {hi, }} ;{ }^{*} P<0.05$ for irradiated control versus SPL $\left.{ }^{\text {hi }}\right)$. (d) Control, SPL ${ }^{\text {hi }}$ and SPL ${ }^{\text {hi }} / \mathrm{ShRNA}_{\mathrm{R}}$ cells were left untreated or irradiated and cells were harvested $36 \mathrm{~h}$ after radiation exposure. Cell cycle distribution was analyzed by flow cytometry using PI staining. The percentage of cells in each stage of the cell cycle is presented for each cell line in comparative bar graph format. Histogram is representative of three different experiments. (e) Blockage of mitotic progression abrogates SPL-mediated apoptosis. Control and SPL hi cells were left untreated or pretreated with a CDK1 inhibitor (Nu6102, $10 \mu \mathrm{M}$ ) for $1 \mathrm{~h}$. Then, cells were irradiated and caspase- 3 activity measured $24 \mathrm{~h}$ after radiation exposure. Data are shown as mean \pm S.D. $\left(n=3,{ }^{* \star} P<0.001\right.$ for SPL ${ }^{\text {hi }}$ irradiated versus $\mathrm{SPL}^{\mathrm{hi}}$ irradiated with $\mathrm{CDK}$ inhibitor) 
Table 1 Ceramide levels in control and SPL ${ }^{\text {hi }}$ cells

\begin{tabular}{|c|c|c|c|c|c|c|c|c|}
\hline \multirow[b]{2}{*}{ Sample } & \multicolumn{7}{|c|}{ Ceramide molecular species } & \multirow[b]{2}{*}{ Total ceramide } \\
\hline & $\mathrm{C} 16$ & C18 & $\mathrm{C2O}$ & $\mathrm{C} 22$ & $\mathrm{C} 24$ & C16-DH & C24-DH & \\
\hline $\begin{array}{l}\text { Control untreated } \\
\text { SPL }{ }^{\text {hi }} \text { untreated } \\
\text { SPL }+ \text { SiRNA untreated } \\
\text { Control+IR } \\
\text { SPL }{ }^{\text {hi }}+\text { IR } \\
\text { SPL } \\
\text { Si }+ \text { SiRNA+IR }\end{array}$ & $\begin{array}{r}6.26 \pm 0.76 \\
8.17 \pm 0.41 \\
6.97 \pm 0.28 \\
8.06 \pm 1.57 \\
12.42 \pm 0.81 \\
9.21 \pm 0.52\end{array}$ & $\begin{array}{l}1.63 \pm 0.05 \\
2.77 \pm 0.21 \\
2.05 \pm 0.12 \\
1.94 \pm 0.35 \\
3.54 \pm 0.20 \\
2.55 \pm 0.19\end{array}$ & $\begin{array}{l}0.25 \pm 0.05 \\
0.35 \pm 0.04 \\
0.29 \pm 0.11 \\
0.28 \pm 0.08 \\
0.53 \pm 0.10 \\
0.32 \pm 0.02\end{array}$ & $\begin{array}{r}1.47 \pm 0.14 \\
2.66 \pm 0.15 \\
2.0 \pm 0.11 \\
1.72 \pm 0.35 \\
3.43 \pm 0.10 \\
2.39 \pm 0.06\end{array}$ & $\begin{array}{r}6.54 \pm 0.61 \\
9.77 \pm 0.51 \\
7.89 \pm 0.90 \\
7.24 \pm 1.07 \\
12.68 \pm 0.86 \\
9.35 \pm 0.51\end{array}$ & $\begin{array}{l}0.24 \pm 0.06 \\
0.27 \pm 0.01 \\
0.24 \pm 0.05 \\
0.26 \pm 0.02 \\
0.39 \pm 0.03 \\
0.24 \pm 0.02\end{array}$ & $\begin{array}{l}0.35 \pm 0.04 \\
0.48 \pm 0.06 \\
0.40 \pm 0.05 \\
0.45 \pm 0.09 \\
0.64 \pm 0.13 \\
0.33 \pm 0.06\end{array}$ & $\begin{array}{l}16.74 \pm 1.56 \\
24.68 \pm 0.84 \\
19.85 \pm 1.24 \\
19.94 \pm 3.47 \\
33.62 \pm 2.27 \\
24.38 \pm 2.27\end{array}$ \\
\hline
\end{tabular}

Abbreviation: $\mathrm{DH}$, dihydroceramide. Control or SPL ${ }^{\text {hi }}$ cells were grown in six-well plate for $24 \mathrm{~h}$. Then, the control or SPL hi cells were either mock transfected or transfected with acid sphingomyelinase siRNA for $48 \mathrm{~h}$, then cells were left untreated or irradiated and harvested $24 \mathrm{~h}$ after radiation exposure (IR). Cellular ceramide was quantitated by LC-MS and are presented as nmoles/mg of phosphatidylcholine. Values are shown as mean \pm S.D.
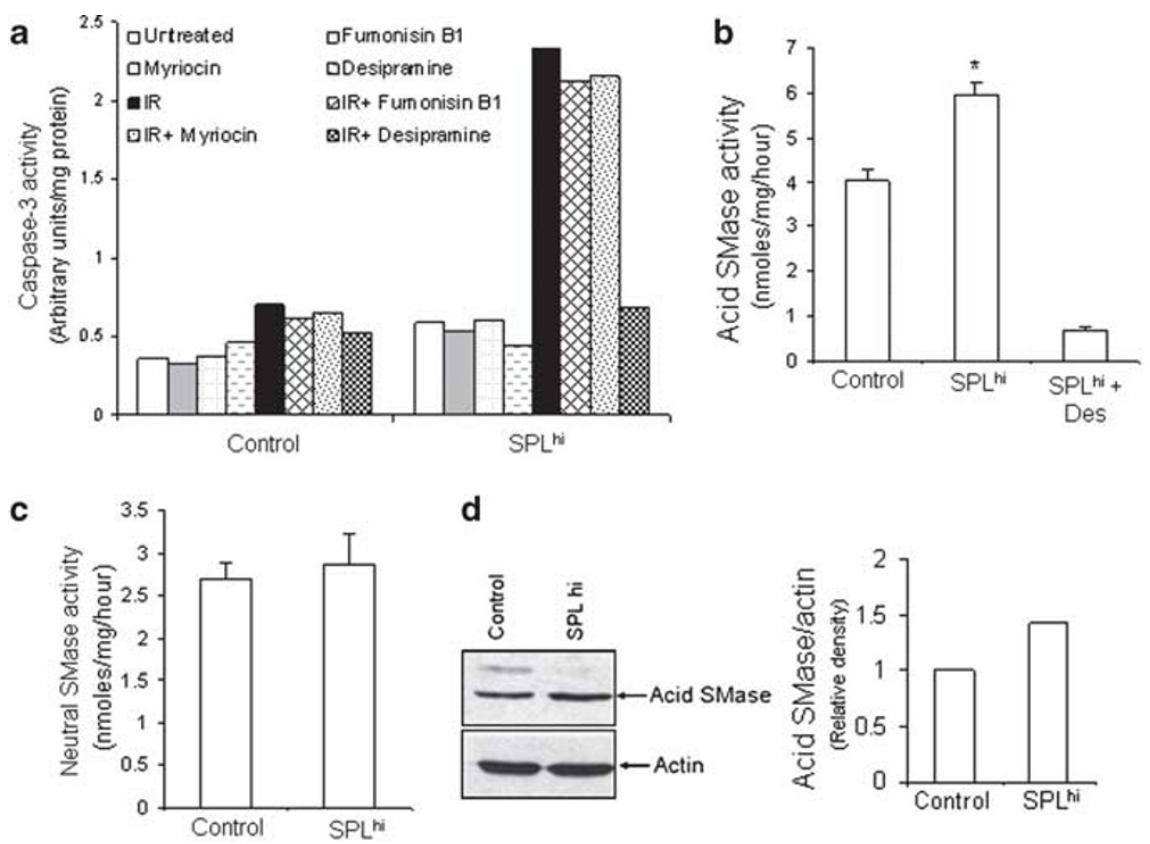

d
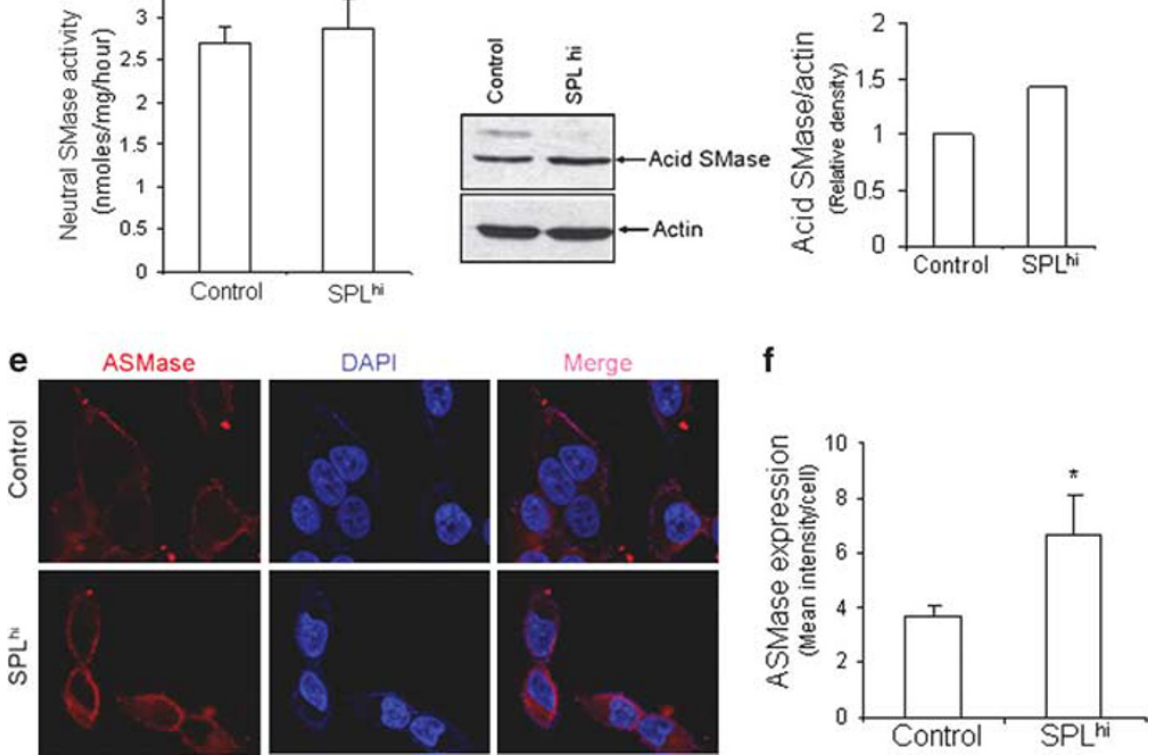

Figure 4 ASMase is activated in the presence of SPL. (a) Inhibition of ASMase by desipramine protects against radiosensitivity of SPL ${ }^{\text {hi }}$ cells, whereas inhibitors of the de novo pathway do not. Control and SPL hi cells were left untreated or pretreated with fumonisin $\mathrm{B} 1(25 \mu \mathrm{M})$, myriocin $(10 \mu \mathrm{M})$ or desipramine $(20 \mu \mathrm{M})$ for $3 \mathrm{~h}$ then cells were irradiated. Caspase- 3 activity was measured $24 \mathrm{~h}$ after radiation exposure. (b and $\mathbf{c}$ ) ASMase activity is upregulated in SPL ${ }^{\mathrm{hi}}$ cells, which was blunted by desipramine. Control and SPL ${ }^{\text {hi }}$ cells $\left(1 \times 10^{6}\right)$ were grown in six-well plate for $24 \mathrm{~h}$. SPL ${ }^{\text {hi }}$ cells were either left untreated or treated with desipramine $(20 \mu \mathrm{M})$ for $6 \mathrm{~h}$. Cells were harvested and then acid (b) and neutral SMase (c) activity was assayed. Data are shown as mean \pm S.D. $\left(n=4,{ }^{*} P<0.001\right.$ (b)). (d) Immunoblotting for ASMase in control and SPL hi cells (left panel). Relative intensity of ASMase expression was quantified by densitometry (right panel). (e) SPL upregulates membrane associated-ASMase. Control and SPL hi cells were grown on poly-L-lysine coated culture slides for $24 \mathrm{~h}$. Immunolabeling was performed for ASMase in fixed, non-permeabilized cells. Images were acquired using a laser scanning microscope (LSM 710). (f) Fluorescence intensity for ASMase was quantitated using NIH ImageJ software. Data are shown as mean \pm S.E.M. $\left(n=2,{ }^{*} P<0.01\right)$ 

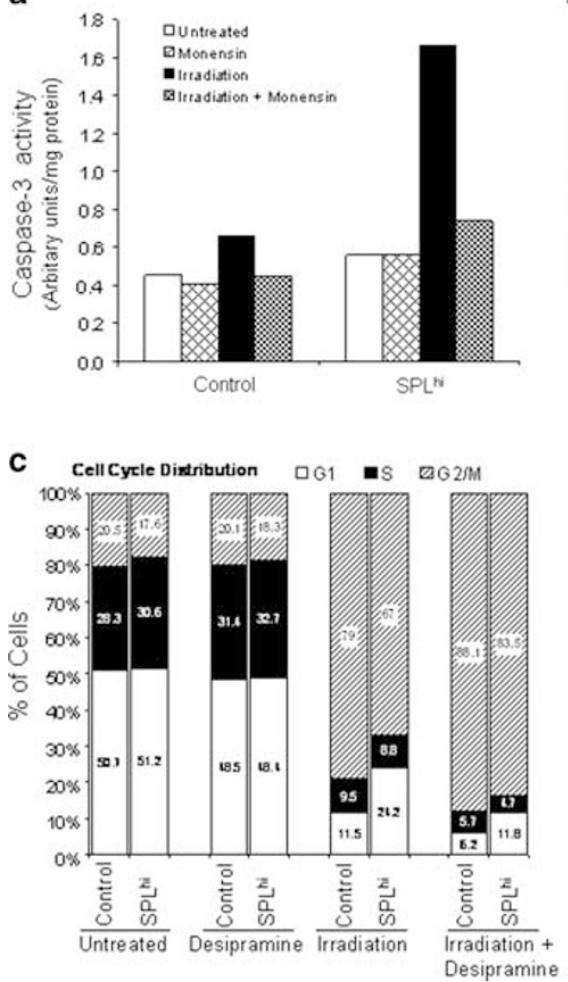

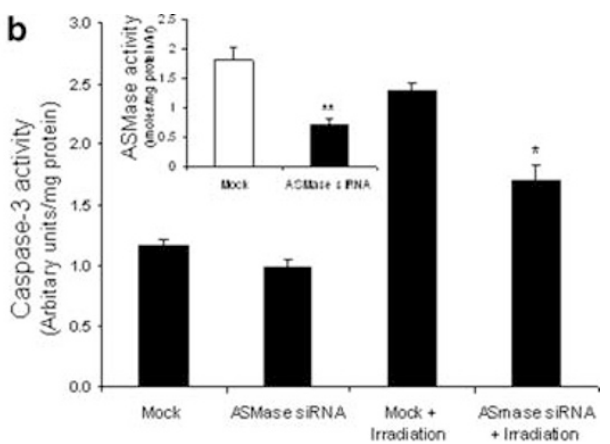

d Cell Cycle Diztribution $\square \mathrm{G} 1 \quad$ as $\quad \mathrm{S} 2 \mathrm{M}$

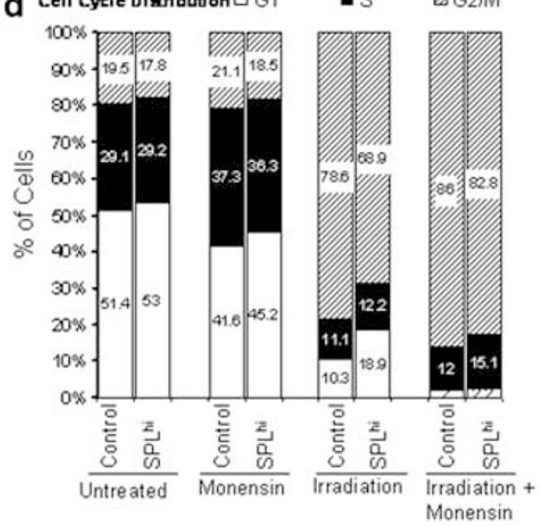

Figure 5 ASMase is responsible for the effects of SPL on the DDR. (a) Control and SPL ${ }^{\text {hi }}$ cells were left untreated or pretreated with Monensin ( $\left.50 \mathrm{nM}\right)$ for $3 \mathrm{~h}$ then cells were exposed to IR and caspase-3 activity was measured $24 \mathrm{~h}$ after radiation exposure. (b) SPL ${ }^{\text {hi }}$ cells were either mock transfected or transfected with siRNA against human ASMase gene (SMPD1). After $48 \mathrm{~h}$, cells were irradiated and harvested after $24 \mathrm{~h}$. ASMase activity in knockdown and mock transfected cells was assayed. Caspase-3 activity was measured using DEVD-pNA as a substrate. Data represent mean \pm S.D. of three independent experiments. $\left({ }^{\star} P<0.01 ;{ }^{* *} P<0.001\right)$. (c and d) Control and SPL ${ }^{\text {hi }}$ cells were pretreated with $20 \mu \mathrm{M}$ desipramine or $250 \mathrm{nM}$ monensin for $3 \mathrm{~h}$. Cells were then exposed to IR and harvested $24 \mathrm{~h}$ after irradiation, and cell cycle distribution was examined by flow cytometry using PI staining. Histograms are representatives of three different experiments

high levels of membrane-associated ASMase compared with control cells. As shown in Supplementary Figure 7, ASMase message levels were not different in the two cell lines, suggesting a translational or posttranslational effect.

Inhibition of ASMase or p38 reverses the radiosensitive phenotype of SPL ${ }^{\text {hi }}$ cells. To confirm the role of ASMase in mediating the effect of SPL on radiation responses, cells were pretreated before IR with monensin, an antibiotic that reduces $A S M a s e$ activity by inhibiting lysosomal acidification. Caspase-3 activity was subsequently determined in whole cell extracts as a measure of IR-induced apoptosis. Figure $5 \mathrm{a}$ shows that chemical inhibition of ASMase attenuates the IR-sensitive phenotype of SPL ${ }^{\text {hi }}$ cells. Inhibition of ASMase also abrogated the accumulation of different ceramide molecular species in SPL ${ }^{\text {hi }}$ after radiation exposure (data not shown). In addition to chemical inhibition of ASMase, siRNA was used to knock down ASMase expression, resulting in a $66 \%$ inhibition of enzyme activity, as shown in Figure $5 \mathrm{~b}$ (inset). Specific knockdown of ASMase partially reversed the sensitization of SPL ${ }^{\text {hi }}$ cells to IR (Figure $5 \mathrm{~b}$ ) and also led to a reduction in ceramide levels in SPL ${ }^{\text {hi }}$ cells, as shown in Table 1.

To determine whether ASMase contributes to the attenuation of $\mathrm{G} 2$ arrest after IR in SPL ${ }^{\text {hi }}$ cells, we pretreated cells with either desipramine or monensin, followed by IR of cells and analysis of cell cycle distribution of living cells $24 \mathrm{~h}$ after IR. As shown in Figures $5 \mathrm{c}$ and $\mathrm{d}, \mathrm{SPL}{ }^{\text {hi }}$ cells behaved similarly to control cells and maintained $\mathrm{G} 2$ cell cycle arrest after IR when ASMase was inhibited. Our findings indicate that both S1P depletion and ceramide generation through the actions of ASMase contribute to the radiosensitive phenotype of SPL ${ }^{\text {hi }}$ cells. Further, the effect of SPL on maintenance of the G2 arrest and resulting increase in apoptosis after radiation requires the expression and activity of ASMase.

The p38 MAPK is required for SPL's ability to promote apoptosis in response to chemotherapy agents ${ }^{16,21}$ and is activated by IR and ceramide. ${ }^{22,23}$ To assess the role of $p 38$ MAPK in SPL-mediated radiosensitization, control and SPL ${ }^{\text {hi }}$ cells were pretreated with the p38 inhibitor SB203580, followed by IR. As shown in Supplementary Figure 8, inhibition of p38 completely prevented apoptosis in response to IR in SPL ${ }^{\text {hi }}$ cells, demonstrating that SPL sensitizes cells to IR through a p38-dependent process.

SPL delays the kinetics of DNA repair. The normal cellular response to DNA damage involves both cell cycle arrest and activation of DNA repair mechanisms. To explore the effects of SPL on DNA repair, we investigated the extent of DNA damage and kinetics of DNA repair after IR in control 
a

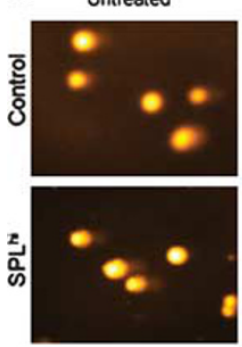

IR 1 min
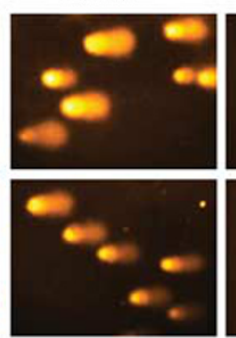

IR $30 \mathrm{~min}$

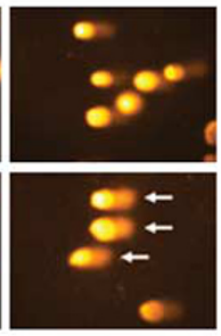

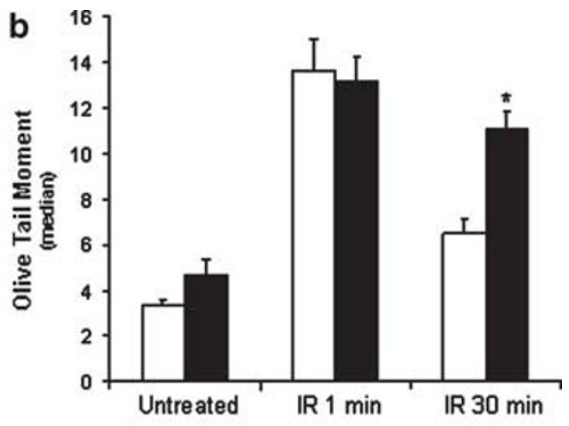
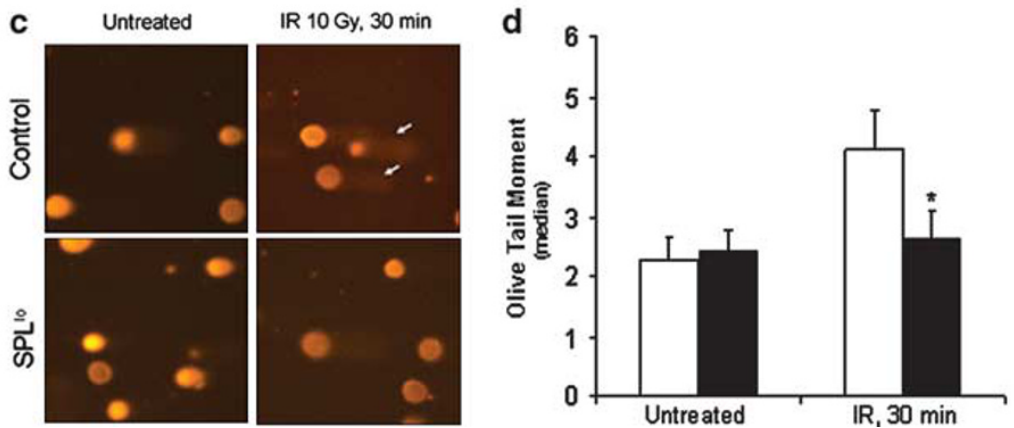

Figure 6 SPL delays the kinetics of DNA repair. (a) Control and SPLi cells were left untreated or irradiated and harvested 1 or 30 min after radiation exposure. Extent of DNA damage was analyzed by comet assay using alkaline electrophoresis. In each sample, 50 cells were scored. (b) Olive tail moment for control (open bar) and SPL ${ }^{\text {hi }}$ (solid bar) cells was analyzed using Komet 6.0 software. (c) Control and SPL ${ }^{10}$ cells were left untreated or irradiated and harvested 30 min after radiation exposure and comet assay was done using neutral electrophoresis. (d) Olive tail moment for control (open bar) and $\mathrm{SPL}^{\mathrm{lo}}$ (solid bar) was analyzed. Photomicrographs and histograms are representative of three independent experiments. (b and $\mathbf{d})$ data represents mean \pm S.D. of three independent experiments $\left({ }^{\star} P<0.01\right.$ )

cells and cells containing high and low levels of SPL using Comet assay. In Figure 6a, Comet assays show that control and SPL ${ }^{\text {hi }}$ cells contain mostly intact DNA under baseline conditions. One minute after IR, control and SPL ${ }^{\text {hi }}$ cells demonstrate evidence of damaged DNA, illustrated by the comet tail. By $30 \mathrm{~min}$, most of the DNA damage has been repaired in control cells, as shown by the lack of comet tails. In contrast, SPL ${ }^{\text {hi }}$ cells continue to exhibit evidence of DNA damage $30 \mathrm{~min}$ after IR. These results are depicted quantitatively using the olive tail moment measurement, as shown in Figure 6b. Conversely, SPL ${ }^{10}$ cells exhibited a greater degree of DNA repair compared with control cells, as shown in Figure $6 \mathrm{c}$ and quantitatively in Figure $6 \mathrm{~d}$. These findings indicate that endogenous SPL has a negative influence on the kinetics and/or efficiency of DNA repair, whereas reducing SPL expression hastens DNA repair after IR.

Inhibition of SPL affords radioprotection in vivo. On the basis of our findings in HEK293T cells, we hypothesized that SPL may function as a target for radioprotection in vivo. To examine this possibility, tetrahydroxybutylimidazole (THI), a food additive that serves as a small molecule inhibitor of SPL, was delivered $(25 \mathrm{mg} / \mathrm{l})$ to mice in the drinking water. ${ }^{24}$ Following 24-h treatment with either THI or vehicle, mice were subjected to 14 Gy total body IR (TBI) and monitored for survival. As shown in Figure 7a, tissue SPL activity was significantly reduced and plasma S1P levels were elevated significantly in mice receiving THI (Figure 7b). Importantly, SPL inhibition afforded radioprotection in vivo as shown by an increase in survival time (Figure 7c) of mice exposed to a lethal dose of TBI. These findings suggest that SPL may serve as a target for radioprotection in vivo.

\section{Discussion}

In this study, we found that SPL is activated by IR and functions as a modulator of the DDR. Specifically, we found that IR-induced G2 cell cycle arrest is initiated properly but is not maintained in cells expressing high levels of SPL, thereby leading to premature entry into mitosis. SPL expression also sensitized cells to IR-induced apoptosis, a characteristic that could be reversed by pretreatment with chemical inhibitors of G2 cell cycle progression. In contrast, SPL-deficient cells were resistant to IR-induced apoptosis. These findings suggest that SPL mediates IR-induced apoptotic cell death through a process that requires mitotic progression. Whether this process involves a form of mitotic death or whether apoptosis is induced later in the progression of the cell cycle will require further study. ${ }^{20}$ Although previous reports have provided evidence that sphingolipid metabolites can influence cell cycle progression, to our knowledge this is the first report linking S1P and SPL to the regulation of cell cycle progression.

The effect of SPL on G2 maintenance was associated with premature activation of the Cdk1-cyclin B complex. G2 arrest involves multiple discrete steps including initiation, maintenance, adaptation and release that occur through distinct mechanisms. For example, maintenance of the G2 arrest depends on reduced levels of the Cdk1-cyclin B complex and p53, whereas initiation of G2 arrest does not depend on p53. ${ }^{25}$ 

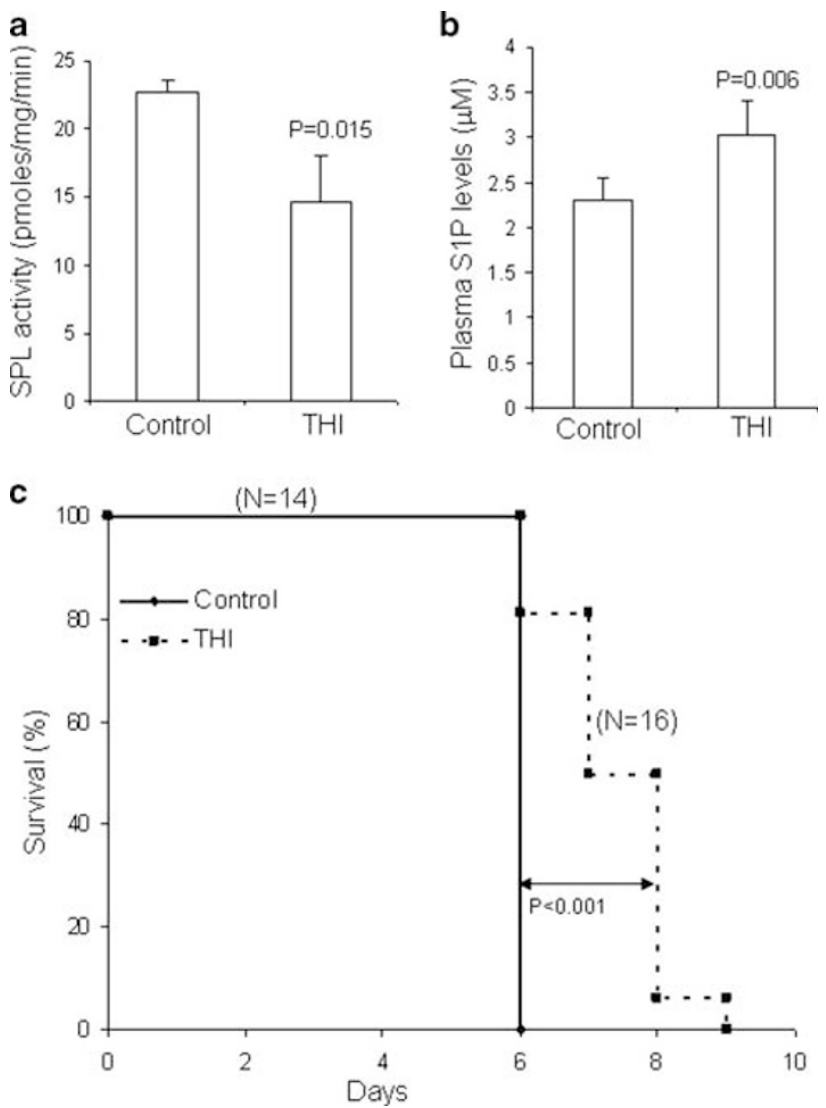

Figure 7 Inhibition of SPL prolongs survival in mice after a lethal dose of radiation. Mice were given THI $(25 \mathrm{mg} / \mathrm{l})$ or vehicle control in the drinking water for $24 \mathrm{~h}$. Following vehicle (control) or $\mathrm{THI}(\mathrm{THI})$ treatment, mice were euthanized. (a) SPL activity was measured in intestine, and (b) plasma S1P levels were quantitated. Values represent the mean \pm S.D. from 3-5 mice in each group. (c) Following vehicle (control, $n=14$ ) or THI (THI, $n=16$ ) treatment, mice were subjected to $14 \mathrm{~Gy} \mathrm{TBI}$ and survival of mice was recorded daily

The mechanism by which SPL influences the Cdk1-cyclin B complex remains to be determined. ${ }^{26}$ Cells respond to DNA damage by activating a complex network of signal transduction pathways. Mutations in different components of the DDR pathways (e.g., ataxia telengiectasia mutated (ATM), BRCA1/2, NBS1 and Mre11) lead to cell cycle checkpoint defects, decreased ability to repair damaged DNA, and an increased sensitivity to IR and other DNA damaging agents. ${ }^{27}$ Interestingly, SPL ${ }^{\text {hi }}$ cells exhibited reduced ATM and checkpoint kinase 1 (Chk1) protein levels compared with control cells, while SPL ${ }^{\text {lo }}$ cells exhibited increased ATM and Chk1 levels (data not shown). However, overexpression of ATM or Chk1 in $\mathrm{SPL}^{\text {hi }}$ cells did not attenuate apoptosis in response to IR. These findings suggest that deficiency of ATM and/or Chk1 are not the primary or at least not the major factors underlying the ability of SPL to influence the DDR.

SPL expression reduces cellular levels of the bioactive sphingolipid, S1P. We found that S1P depletion by SPL sensitizes cells to radiation, consistent with previous reports indicating that S1P acts as a radioprotectant in ovaries, gut and endothelium. ${ }^{14,28}$ However, the radiosensitive phenotype of SPL ${ }^{\text {hi }}$ cells could not be fully reversed using strategies to restore cellular S1P levels. This led to the discovery that cells expressing SPL accumulate ceramide through an ASMasedependent mechanism. Further, ASMase expression, activity and ASMase-dependent ceramide accumulation were required for the ability of SPL to abbreviate cell cycle arrest and promote apoptosis of irradiated cells. These findings are consistent with the important role of ASMase in radiation responsiveness and reveal an unexpected positive feedback loop linking ceramide catabolism to ceramide recycling from membrane sphingomyelin. It is likely that by raising ceramide levels, SPL lowers the threshold required to activate apoptosis in response to DNA damage. Inhibition of p38 also blocked apoptosis in SPL ${ }^{\text {hi }}$ cells after IR, consistent with a role for this stress-activated kinase in the pro-apoptotic actions of both ceramide and SPL.

Cellular ASMase activity is regulated at transcriptional and posttranslational levels. ${ }^{29}$ Additional mechanisms of regulation involve the trafficking of ASMase to the lysosome, the outer leaflet of the plasma membrane, and its secretion into the extracellular space. In particular, recent studies suggest that membrane-translocated ASMase generates the ceramide pool that promotes apoptosis after exposure to IR. ${ }^{30}$ Our finding of increased total cellular ASMase protein levels and increased membrane-associated ASMase in SPL ${ }^{\text {hi }}$ cells may point to a potential role for SPL in these processes.

Finally, we demonstrate that downregulation of SPL leads to increased DNA repair kinetics in vitro. Importantly, we also show that administration of the nontoxic food additive $\mathrm{THI}$ to mice reduces SPL activity, raises plasma S1P levels and significantly prolongs animal survival after a lethal dose of TBI. SPL null mice exhibit developmental defects, lymphocyte trafficking defects and death within 1-2 months after birth. Whereas chronic and complete inhibition of SPL may therefore not be advisable, partial inhibition of SPL using THI and other chemical inhibitors of SPL is a strategy that has been recently exploited for immunomodulatory purposes and appears to be well tolerated. ${ }^{24,31}$ Thus, we propose that SPL inhibition using these or similar agents may be a useful strategy for achieving radioprotection in acute situations such as the delivery of therapeutic radiation in cancer patients or to mitigate injury after accidental radiation exposure.

\section{Materials and Methods}

Materials. Dimethyl sulfoxide, BSA, desipramine, paraformaldehyde, propidium iodide, RNaseA, polybrene, puromycin and crystal violet were from Sigma (St. Louis, MO, USA); S1P was from Matreya, LLC (Pleasant Gap, PA, USA). Fumonisin B1 and myriocin were from Cayman (Ann Arbor, MI, USA). NBD-S1P was from Avanti Polar Lipids (Alabaster, AL, USA). Monensin and Nu6102 were from Enzo Life Science (Plymouth Meeting, PA, USA). THI was from Albany Molecular Research Inc. (Albany, NY, USA). [Choline-methyl- $\left.{ }^{14} \mathrm{C}\right] \mathrm{SM}$ is from American Radiolabeled Chemicals (St. Louis, MO, USA).

Cell culture and irradiation. Stable clones of human SPL-GFP fusion protein or pcDNA 3.0 vector were generated in human embryonic kidney (HEK293T) as described. ${ }^{17}$ Cells were propagated in Dulbecco's modified Eagle's medium with high glucose (Cell culture facility, UCSF, San Francisco, CA, USA) containing $10 \%$ fetal bovine serum (JR Scientific, Woodland, CA, USA), penicillin (100 units $/ \mathrm{ml})$ and streptomycin $(100 \mu \mathrm{g} / \mathrm{ml})$, at $37^{\circ} \mathrm{C}$ with $5 \% \mathrm{CO}_{2}$. Cells were irradiated at room temperature with an X-ray generator, RS-2000 Biological Irradiator (Rad Source Technologies, Inc., Alpharetta, GA, USA) operating at $160 \mathrm{kV}$ and $25 \mathrm{~mA}$, yielding an absorbed dose rate of $2.2 \mathrm{~Gy} / \mathrm{min}$. Unless otherwise stated, cells were irradiated with 10 Gy dose of IR. 
Generation of SK1 overexpressing cells. Plasmid eGFP-SK1-Flag (generous gift of Stuart Pitson ${ }^{32}$ ) was first digested with Hindlll and treated with Klenow fragment of $E$. coli DNA polymerase to fill in the $5^{\prime}$-overhang and was then cut with $E c O R I$ to release the GFP-SK1 fragment. Following gel purification, this fragment was ligated to a sequentially digested pBabe-Puro, first with $\mathrm{BamHI}$ and blunted as above, and then with EcoRI. Transfection of the resultant plasmid into HEK293T-SPL ${ }^{\text {hi }}$ cells was performed via the $\mathrm{Ca}_{2} \mathrm{PO}_{4}$ precipitation method and stable clones were established by selection on $2 \mu \mathrm{g} / \mathrm{ml}$ puromycin for 3 weeks. ${ }^{33}$

ASMase siRNA. Cells were plated in six-well plates in DMEM H-21 containing $10 \%$ FBS without antibiotics. After $24 \mathrm{~h}, 100 \mathrm{nM}$ ASMase (SMPD1) siRNA (Dharmacon, Lafayette, CO, USA) were transfected with Lipofectamine 2000. Control cells were similarly treated with non-targeting siRNA control. At $48 \mathrm{~h}$ after transfection, the cells were exposed to IR.

SPL knockdown. The lentiviral vector pLKO.1 (Addgene plasmid 10878) was used to clone shRNAs targeting the human SPL gene Sgpl1 according to pLKO.1 protocol (http://www.addgene.com). The virions were produced by transfection of HEK293T cells using the recombinant pLKO.1 along with packaging plasmid psPAX2 (Addgene plasmid 12260) and the envelope-encoding plasmid pMD2.G (Addgene plasmid 12259). At $48 \mathrm{~h}$ post-transfection, the spent media containing the lentiviral particles was collected. This was used to infect control and SPL ${ }^{\text {hi }}$ cells in the presence of $8 \mu \mathrm{g} / \mathrm{ml}$ polybrene. Stable clones were selected with puromycin $(1.5 \mu \mathrm{g} / \mathrm{ml})$. The surviving colonies were screened for human SPL expression levels using RT-PCR or western blotting.

Caspase 3 activity. Caspase-3 substrate Ac-DEVD-pNA was from Enzo Life Sciences. Caspase-3 assays were performed as described. ${ }^{17}$

RT-PCR. Total RNA was isolated from cells using Trizol reagent (Invitrogen, Carlsbad, CA, USA) according to the manufacturer's instructions. Primers for human Sgp/1 and actin were: Sgp/1 forward 5'-GATAGAGGCAGAAATTGTGAGG ATA-3', Sgpl1 reverse 5'-GTATTTTGTATTTGACAGCCAGCTT-3', actin forward $5^{\prime}$-AGAAAATCTGGCACCACACC-3' and actin reverse 5'-AGAGGCGTACAGGGA TAGCA-3'. RT-PCR was performed using the one-step RT-PCR kit (Qiagen, Valencia, CA, USA).

Immunoblotting. Immunoblotting was performed as described. ${ }^{16}$ Antibodies to PARP, cyclin B1, CDK1, ASMase and HRP-conjugated anti-rabbit and antimouse antibodies were from Cell Signaling Technologies (Beverly, MA, USA). Antibody to actin was from Sigma. Antibody to phospho-histone H3 (Ser10) was from Millipore (Billerica, MA, USA). Histone H3 antibody was from Genscript Inc. (Piscataway, NJ, USA). Antibodies against SPL were described previously. ${ }^{16}$ SK1 antibody was from Abcam (Cambridge, MA, USA). Relative intensities of autoradiogram bands were quantitated using NIH ImageJ (http://rsbweb.nih.gov/ij/).

Comet assay. Control, SPL ${ }^{\text {hi }}$ or SPL ${ }^{10}$ cells $0.5 \times 10^{6}$ were plated in six-well plates and propagated for $24 \mathrm{~h}$. Cells were mock-treated or given $10 \mathrm{~Gy}$ of radiation. Cells were rested at $37^{\circ} \mathrm{C}$ for the indicated times, and alkaline or neutal comet assay was performed using the Comet Assay kit (Trevigen, Gaithersburg, MD, USA). Comet images stained with $1 \mu \mathrm{g} / \mathrm{ml}$ SYBRGreen (Trevigen) were captured using an inverted fluorescent microscope (Axiovert 200, Carl Zeiss, Thornwood, NY, USA). Olive tail moment was analyzed using Komet 5.0 software (Andor Technology, South Windsor, CT, USA).

Cell cycle analysis. Cells $\left(1 \times 10^{6}\right)$ were collected by trypsinization and washed with PBS. Cells were fixed in chilled $70 \%$ ethanol for $1 \mathrm{~h}$ on ice. After washing with PBS, cells were stained with a solution containing $40 \mu \mathrm{g} / \mathrm{ml}$ propidium iodide and $100 \mu \mathrm{g} / \mathrm{ml}$ of RNase A. Cells were evaluated for DNA content using a FACSCalibur (Becton Dickinson, San Jose, CA, USA) flow cytometer. Data were analyzed by CellQuest Pro software (Becton Dickinson). Dead cells and aggregates were excluded from analysis by gating cells in a FL2-A versus FL2-W scatter plot.

Immunocytometry. Cells $\left(1 \times 10^{6}\right)$ were collected by trypsinization and after washing were fixed in ice-cold $70 \%$ ethanol for up to $24 \mathrm{~h}$ at $-20^{\circ} \mathrm{C}$. After washing, cells were permeabilized with $0.25 \%$ Triton-X 100 in PBS for 15 min on ice. After blocking, cells were stained with antibody against S10 H3 Ser 10 (Millipore) for $1 \mathrm{~h}$ at room temperature, followed by incubation with Alexa Fluor 555 conjugated goat anti-rabbit antibody (Invitrogen). Cellular fluorescence was monitored with a
FACSCalibur (Becton Dickinson) flow cytometer. Data were analyzed by CellQuest Pro software.

Detection of ceramide and ASMase surface expression by confocal microscopy. Control and SPLi cells were grown for $24 \mathrm{~h}$ on poly-L-lysine coated eight-well chamber slides (BD Biosciences, San Jose, CA, USA). To detect ceramide, cells were washed in cold PBS and fixed for $15 \mathrm{~min}$ in $4 \%$ paraformaldehyde. After washing, cells were permeabilized with $0.3 \%$ Triton-X-100 in PBS for 10 min at room temperature. Cells were blocked with $5 \%$ goat serum and $0.1 \%$ Triton- $\mathrm{X}-100$ in PBS for $1 \mathrm{~h}$ at room temperature. Cells were stained with primary antibody to ceramide (Alexis Corporation, Lausen, Switzerland) overnight at $4{ }^{\circ} \mathrm{C}$, washed three times in PBS, and stained with Cy3-conjugated secondary antibody (Jackson Immunoresearch Laboratories, Inc., West Grove, PA, USA) for $1 \mathrm{~h}$ at room temperature. To detect surface expression of ASMase, cells were processed as described above, except that cells were not permeabilized, and Triton$\mathrm{X}-100$ was excluded from blocking and antibody incubation buffer. To detect surface expression of ASMase, cells were stained with primary antibody to ASMase (Santa Cruz Biotechnology, Santa Cruz, CA, USA) overnight at $4{ }^{\circ} \mathrm{C}$, washed three times in PBS, and stained with Cy3-conjugated secondary antibody (Jackson Immunoresearch Laboratories, Inc.) for $1 \mathrm{~h}$ at room temperature. Nonspecific fluorescence was excluded by performing a control without primary antibody. Cells were washed three times, stained with DAPI and mounted in mounting medium. Images were captured using a laser scanning microscope and software (LSM 710, Carl Zeiss, Inc.). Images were processed using Adobe Photoshop (Adobe, San Jose, CA, USA). Fluorescence intensity was quantitated using NIH ImageJ software.

SMase assay. SMase assay was performed using [choline-methyl- $\left.{ }^{14} \mathrm{C}\right] \mathrm{SM}$ substrate as described. ${ }^{28}$

Sphingolipid quantitation. S1P and total ceramide were quantitated as described. ${ }^{17,34}$

Mice irradiation and survival of mice. C57BL/6 female mice (8-12 weeks old) were from Charles River Laboratory (Wilmington, MA, USA). TBI was delivered with a ${ }^{137} \mathrm{Cs}$ irradiator (Shepherd Mark-I, JL Shepherd \& Associates, San Fernando, CA, USA) at a dose rate of $2.41 \mathrm{~Gy} / \mathrm{min}$. ${ }^{35}$ Before TBI, mice were given vehicle control or THI $(25 \mathrm{mg} / \mathrm{l})$ in the drinking water for $24 \mathrm{~h}$. Actuarial survival was calculated by the product-limit Kaplan-Meier method, and $P$-values were evaluated by the Mantel log-rank test. ${ }^{35}$

SPL assay. SPL activity was measured in mouse intestine using a fluorescent NBD-S1P substrate. ${ }^{36}$

Statistical analysis. Comparison between two groups was carried out by unpaired Student's t-test. Survival curve was plotted by the product-limit Kaplan-Meier method, and $P$-values were evaluated by the Mantel log-rank test using SPSS software (Chicago, IL, USA).

\section{Conflict of interest}

The authors declare no conflict of interest.

Acknowledgements. This work was supported by National Institutes of Health Grants CA77528 and Al078516 (JDS), RC1 ARRA supplemental grant and generous support from the Swim Across America Foundation (BO). We thank Damir Sudar (Lawrence Berkeley National Laboratories) for assistance with confocal microscopy, and John Murnane and Gloria Reynolds (University of California at San Francisco) and Eleanor Blakely and Kathy Bjornstad (Lawrence Berkeley National Laboratories) for assistance with mouse irradiation.

\section{Author contributions}

AK designed and performed the experiments, analyzed data and helped write the paper. BO generated molecular constructs used throughout the study and performed experiments and analyzed data. HF, FP and MZ performed experiments and analyzed data. JDS designed experiments, supervised the project and wrote the paper. All authors discussed the results and implications and commented on the paper at all stages. 
1. Lobrich $M$, Jeggo PA. The impact of a negligent $G 2 / M$ checkpoint on genomic instability and cancer induction. Nat Rev Cancer 2007; 7: 861-869.

2. Potapova T, Daum J, Byrd K, Gorbsky G. Fine tuning the cell cycle: activation of the Cdk1 inhibitory phosphorylation pathway during mitotic exit. Mol Biol Cell 2009; 20: 1737-1748.

3. Quintans J, Kilkus J, McShan C, Gottschalk A, Dawson G. Ceramide mediates the apoptotic response of WEHI 231 cells to anti-immunoglobulin, corticosteroids and irradiation. Biochem Biophys Res Commun 1994; 202: 710-714.

4. Lin X, Fuks Z, Kolesnick R. Ceramide mediates radiation-induced death of endothelium. Crit Care Med 2000; 28: N87-N93.

5. Huang C, Ma W, Ding M, Bowden GT, Dong Z. Direct evidence for an important role of sphingomyelinase in ultraviolet-induced activation of c-Jun N-terminal kinase. J Biol Chem 1997; 272: 27753-27757.

6. Sathishkumar S, Boyanovsky B, Karakashian AA, Rozenova K, Giltiay NV, Kudrimoti M et al. Elevated sphingomyelinase activity and ceramide concentration in serum of patients undergoing high dose spatially fractionated radiation treatment: implications for endothelial apoptosis. Cancer Biol Ther 2005; 4: 979-986.

7. Haimovitz-Friedman A, Kan C, Ehleiter D, Persaud R, McLoughlin M, Fuks Z et al. Ionizing radiation acts on cellular membranes to generate ceramide and initiate apoptosis. $J$ Exp Med 1994; 180: 525-535.

8. Kolesnick R, Fuks Z. Radiation and ceramide-induced apoptosis. Oncogene 2003; 22 5897-5906.

9. Rodriguez-Lafrasse C, Alphonse G, Aloy MT, Ardail D, Gerard JP, Louisot P et al. Increasing endogenous ceramide using inhibitors of sphingolipid metabolism maximizes ionizing radiation-induced mitochondrial injury and apoptotic cell killing. Int J Cancer 2002; 101: 589-598.

10. Santana P, Pena L, Haimovitz-Friedman A, Martin S, Green D, McLoughlin M et al. Acid sphingomyelinase-deficient human lymphoblasts and mice are defective in radiationinduced apoptosis. Cell 1996; 86: 189-199.

11. Hwang D, Popat R, Bragdon C, O'Donnell KE, Sonis ST. Effects of ceramide inhibition on experimental radiation-induced oral mucositis. Oral Surg Oral Med Oral Pathol Oral Radiol Endod 2005; 100: 321-329.

12. Hla T. Physiological and pathological actions of sphingosine 1-phosphate. Semin Cell Dev Biol 2004; 15: 513-520.

13. Otala M, Suomalainen L, Pentikainen M, Kovanen $\mathrm{P}$, Tenhunen $\mathrm{M}$, Erkkila $\mathrm{K}$ et al. Protection from radiation-induced male germ cell loss by sphingosine-1-phosphate. Biol Reprod 2004; 70: 759-767.

14. Morita Y, Perez Gl, Paris F, Miranda SR, Ehleiter D, Haimovitz-Friedman A et al. Oocyte apoptosis is suppressed by disruption of the acid sphingomyelinase gene or by sphingosine-1-phosphate therapy. Nat Med 2000; 6: 1109-1114.

15. Kumar A, Saba JD. Lyase to live by: sphingosine phosphate lyase as a therapeutic target Expert Opin Ther Targets 2009; 13: 1013-1025.

16. Oskouian B, Sooriyakumaran P, Borowsky A, Crans A, Dlllard-Telm L, Tam Y et al Sphingosine-1-phosphate lyase potentiates apoptosis via p53- and p38-dependent pathways and is downregulated in colon cancer. Proc Natl Acad Sci USA 2006; 103 17384-17389.

17. Reiss U, Oskouian B, Zhou J, Gupta V, Sooriyakumaran P, Kelly S et al. Sphingosinephosphate lyase enhances stress-induced ceramide generation and apoptosis. $J$ Biol Chem 2004; 279: 1281-1290.

18. Min J, Stegner A, Alexander H, Alexander S. Overexpression of sphingosine-1-phosphate lyase or inhibition of sphingosine kinase in Dictyostelium discoideum results in a selective increase in sensitivity to platinum-based chemotherapy drugs. Eukaryotic Cell 2004; 3: 795-805.

19. Colie S, Van Veldhoven PP, Kedjouar B, Bedia C, Albinet V, Sorli SC et al. Disruption of sphingosine 1-phosphate lyase confers resistance to chemotherapy and promotes oncogenesis through Bcl-2/Bcl-xL upregulation. Cancer Res 69: 9346-9353.

20. Castedo M, Perfettini J, Roumier T, Kroemer G. Cyclin-dependent kinase-1: linking apoptosis to cell cycle and mitotic catastrophe. Cell Death Differ 2002; 9: 1287-1293.

21. Min J, Van Veldhoven PP, Zhang L, Hanigan MH, Alexander H, Alexander S. Sphingosine1-phosphate lyase regulates sensitivity of human cells to select chemotherapy drugs in a p38-dependent manner. Mol Cancer Res 2005; 3: 287-296.

22. Kumar P, Miller Al, Polverini PJ. P38 MAPK mediates gamma-irradiation-induced endothelial cell apoptosis, and vascular endothelial growth factor protects endothelial cells through the phosphoinositide 3-kinase-Akt-Bcl-2 pathway. J Biol Chem 2004; 279: 43352-43360.

23. Chen C, Lin C, Chang W, Huang W, Teng C, Lin Y. Ceramide induces p38 MAPK and JNK activation through a mechanism involving a thioredoxin-interacting protein-mediated pathway. Blood 2008; 111: 4365-4374.

24. Schwab S, Pereira J, Matloubian M, Xu Y, Huang Y, Cyster J. Lymphocyte sequestration through S1P lyase inhibition an disruption of S1P gradients. Science 2005; 309: 1735-1739.

25. DeSimone JN, Bengtsson U, Wang X, Lao XY, Redpath JL, Stanbridge EJ. Complexity of the mechanisms of initiation and maintenance of DNA damage-induced G2-phase arrest and subsequent G1-phase arrest: TP53-dependent and TP53-independent roles. Radiat Res 2003; 159: 72-85.

26. DiPaola RS. To arrest or not to G(2)-M Cell-cycle arrest : commentary re: AK Tyagi et al., Silibinin strongly synergizes human prostate carcinoma DU145 cells to doxorubicininduced growth inhibition, G(2)-M arrest, and apoptosis. Clin Cancer Res 8: 3512-3519, 2002. Clin Cancer Res 2002; 8: 3311-3314.

27. Burdak-Rothkamm S, Prise KM. New molecular targets in radiotherapy: DNA damage signalling and repair in targeted and non-targeted cells. Eur J Pharmacol 2009; 625: 151-155.

28. Paris F, Perez G, Fuks Z, Haimovitz-Friedman A, Nguyen H, Bose M et al. Sphingosine-1phosphate preserves fertility in irradiated female mice without propagating genomic damage in offspring. Nat Med 2002; 8: 901-902.

29. Schuchman $E$. Acid sphingomyelinase, cell membranes and human disease: lessons from Niemann-Pick disease. FEBS Lett 2010; 584: 1895-1900.

30. Jenkins R, Canals D, Hannun Y. Roles and regulation of secretory and lysosomal acid sphingomyelinase. Cell Signal 2009; 21: 836-846.

31. Vogel P, Donoviel M, Read R, Hansen G, Hazlewood J, Anderson S et al. Incomplete inhibition of sphingosine 1-phosphate lyase modulates immune system function yet prevents early lethality and non-lymphoid lesions. PLOS ONE 2009; 4: e4112.

32. Pitson SM, Moretti PA, Zebol JR, Lynn HE, Xia P, Vadas MA et al. Activation of sphingosine kinase 1 by ERK1/2-mediated phosphorylation. EMBO $\mathrm{J} 2003 ; 22$ : 5491-5500.

33. Graham $F$, van der Eb A. A new technique for the assay of infectivity of human adenovirus 5 DNA. Virology 1973; 52: 456-467.

34. Tauseef M, Kini V, Knezevic N, Brannan M, Ramchandaran R, Fyrst $\mathrm{H}$ et al. Activation of sphingosine kinase-1 reverses the increase in lung vascular permeability through sphingosine-1-phosphate receptor signaling in endothelial cells. Circ Res 2008; 103: 1164-1172.

35. Paris F, Fuks Z, Kang A, Capodieci P, Juan G, Ehleiter D et al. Endothelial apoptosis as the primary lesion initiating intestinal radiation damage in mice. Science 2001; 293: 293-297.

36. Bandhuvula $P$, Fyrst $H$, Saba J. A rapid fluorescent assay for sphingosine-1-phosphate lyase enzyme activity. J Lipid Res 2007; 48: 2769-2778.

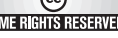

Cell Death and Disease is an open-access journal published by Nature Publishing Group. This work is licensed under the Creative Commons Attribution-Noncommercial-No Derivative Works 3.0 Unported License. To view a copy of this license, visit http://creativecommons.org/licenses/by-nc-nd/3.0/

\section{Supplementary Information accompanies the paper on Cell Death and Disease website (http://www.nature.com/cddis)}

